\title{
A influência do quórum sensing na formação do biofilme por Pseudomonas
}

\section{aeruginosa}

\author{
The influence of the quorum sensing on the formation of biofilm by Pseudomonas aeruginosa
}

La influencia de la percepción de quorum en la formación de biofilm por Pseudomonas aeruginosa

\author{
Marina Luizy Rocha Neves \\ ORCID: https://orcid.org/0000-0002-7949-6605 \\ Universidade Federal de Pernambuco, Brasil \\ E-mail: marinaluizy@ hotmail.com \\ Luanne Eugênia Nunes \\ ORCID: https://orcid.org/0000-0001-6524-0994 \\ Faculdade Nova Esperança de Mossoró, Brasil \\ E-mail: luanne_87@hotmail.com \\ Wilma Raianny Vieira da Rocha \\ ORCID: https://orcid.org/0000-0001-8126-8153 \\ Universidade Federal de Pernambuco, Brasil \\ E-mail: wilmaraianny@gmail.com \\ Eulália Camelo Pessoa de Azevedo Ximenes \\ ORCID: https://orcid.org/0000-0002-4486-0374 \\ Universidade Federal de Pernambuco, Brasil \\ E-mail: eulaliaximenes@yahoo.com.br \\ Mônica Camelo Pessoa de Azevedo Albuquerque \\ ORCID: https://orcid.org/0000-0002-2882-6563 \\ Universidade Federal de Pernambuco, Brasil \\ E-mail: monica.aalbuquerque@ufpe.br
}

\begin{abstract}
Resumo
As bactérias se organizam de forma agregada numa matriz extracelular, chamada biofilme, estrutura que confere proteção a bactéria a ação dos antimicrobianos e a resposta imune do hospedeiro. Assim, Pseudomonas aeruginosa, é classificado como um micro-organismo oportunista, responsável por causar altos números de infecções hospitalares devido a resistência bacteriana desenvolvida por fatores de virulência como o biofilme, controlados por o sistema quorum sensing. Desse modo, o objetivo desse trabalho foi descrever a comunicação das células bacteriana para formação do biofilme por $P$. aeruginosa, durante o processo de colonização e infecção no hospedeiro. Seguiu-se a metodologia de uma revisão narrativa, com base nos artigos publicados entre os anos de 2000 e 2020, indexados na Biblioteca Virtual em Saúde (BVS), utilizando para busca os descritores: "quorum sensing", "Pseudomonas aeruginosa", "biofilm", "virulence factors", "Flagella", "pili", "bacterial adhesion" "polysaccharide" "adhesins" e "biofilm matrix". Foram selecionados artigos publicados na íntegra, em inglês, entre os anos de 1990 e 2020. Foram excluídos artigos incompletos, duplicados e trabalhos acadêmicos como teses e dissertações. Evidenciou-se que a resistência bacteriana de $P$. aeruginosa aos antibióticos está relacionada a sua alta capacidade de adaptação a ambientes hostis e aos mecanismos de resistência desenvolvidos pela espécie, especialmente a formação do biofilme bacteriano pelo sistema quorum sensing a partir da biossíntese de moléculas autoindutoras como: N-3-oxo-dodecanoil homoserina lactona, N-butanoil-homoserina lactona e 2-heptil-3-hidroxi-4-quinolona, responsáveis por mediar a produção dos fatores de virulência. Esta revisão abordou os aspectos gerais que envolve a patogenicidade oriunda da comunicação bacteriana durante o seu processo de colonização.
\end{abstract}

Palavras-chave: Fatores de virulência; Biofilme; Resistência bacteriana a antibióticos; Infecção hospitalar.

\begin{abstract}
The bacteria are organized in an aggregated form in an extracellular matrix, called biofilm, a structure that gives protection to the bacteria, the action of antimicrobials and the hosts immune response. Therefore, Pseudomonas aeruginosa, is classified as an opportunistic microorganism, responsible for causing high numbers of nosocomial infections due to bacterial resistance developed by virulence factors such as biofilm, controlled by the quorum sensing system. Thereby, the objective of this work was to describe the communication of bacterial cells for the formation of biofilm by $P$. aeruginosa, during the process of colonization and infection in the host. This was followed by the methodology of a narrative review, based on articles published between 1990 and 2020, indexed in the Biblioteca Virtual em Saúde (BVS), using the descriptors: "quorum sensing", "Pseudomonas aeruginosa", "biofilm", "virulence factors", "Flagella", "pili", "bacterial adhesion" "polysaccharide" "adhesins" and "biofilm matrix". Articles published in full, in English, between 2000 and 2020 were selected Incomplete articles, duplicates and academic papers such as
\end{abstract}


theses and dissertations were excluded. The studies demonstrated that the bacterial resistance of $P$. aeruginosa to antibiotics is related to its high capacity to adapt to hostile environments and to the resistance mechanisms developed by the species, especially the formation of bacterial biofilm by the quorum sensing system from the biosynthesis of self-inducing molecules such as: N-3-oxo-dodecanoyl homoserine lactone, N-butanoyl-homoserin lactone and 2heptyl-3-hydroxy-4-chi nolona, responsible for mediating the production of virulence factors. This review addressed the general aspects involving the pathogenicity arising from bacterial communication during its colonization process.

Keywords: Virulence factors; Biofilm; Drug resistance bacterial; Cross infection.

\section{Resumen}

Las bacterias se organizan de forma agregada en una matriz extracelular, denominada biopelícula, una estructura que protege a las bacterias, la acción de los antimicrobianos y la respuesta inmunitaria del huésped. Así, Pseudomonas aeruginosa, se clasifica como un microorganismo oportunista, responsable de provocar un elevado número de infecciones nosocomiales debido a la resistencia bacteriana desarrollada por factores de virulencia como el biofilm, controlado por el sistema de detección de quórum. De ese modo, el objetivo de este trabajo fue describir la comunicación de las células bacterianas para la formación de biofilm por $P$. aeruginosa, durante el proceso de colonización e infección en el hospedador. Se siguió una metodología de revisión narrativa, basada en artículos publicados entre 2000 y 2020, indexados en la Biblioteca Virtual de Saúde (BVS), utilizando los descriptores: "quorum sensing", "Pseudomonas aeruginosa", " biofilm "," factores de virulencia "," Flagella ", " pili "," bacterial adhesion "'" polisacárido "'" adhesinas " $y$ " biofilm matrix ". Se seleccionaron artículos publicados íntegramente, en inglés, entre 2000 y 2020. Se excluyeron artículos incompletos, duplicados y trabajos académicos como tesis y disertaciones, y se demostró que la resistencia bacteriana de P. aeruginosa a los antibióticos está relacionada con su alta capacidad de adaptación a ambientes hostiles y a los mecanismos de resistencia desarrollados por la especie, especialmente la formación. de biopelícula bacteriana por el sistema de detección de quórum basado en la biosíntesis de moléculas autoinductoras tales como: N-3-oxo-dodecanoil homoserina lactona, N-butanoil-homoserina lactona y 2heptil-3-hidroxi-4-quinolona, resp. para mediar en la producción de factores de virulencia. Esta revisión abordó los aspectos generales relacionados con la patogenicidad derivada de la comunicación bacteriana durante su proceso de colonización.

Palabras clave: Factores virulentos; Biofilm; Farmacorresistencia bacteriana; Infección hospitalaria.

\section{Introdução}

Pseudomonas aeruginosa é um bacilo Gram-negativo encontrado amplamente na natureza e se adapta aos mais distintos ambientes, como água, solo, tecidos de plantas e animais. Conhecido como um patógeno oportunista, $P$. aeruginosa é responsável por causar vários tipos de infecções, especialmente em pacientes imunocomprometidos ou portadores de fibrose cística (Johansen et al., 1998; Davies, 2002).

Ao aderir a uma superfície, o bacilo inicia seu processo de colonização, a partir da produção de uma matriz tridimensional chamada de biofilme, composta por exopolissacarídeos, alginatos, eDNA, proteínas e lipídios (Flemming \& Wingender, 2010). Após colonizar o hospedeiro, P. aeruginosa inicia uma comunicação entre suas células, por um sistema chamado de quorum sensing. Este é formado por três sistemas de comunicação las, rhl e pqs, que são controlados por moléculas autoindutoras como: N-3-oxo-dodecanoil homoserina lactona, N-butanoil-homoserina lactona e 2-heptil-3-hidroxi4-quinolona (Kariminik, Baseri-Salehi \& Kheirkhah, 2017). Que são responsáveis pela expressão de fatores de virulência, como: raminolipídeos, piocianina, alginato e elastase, que agem lesionando o tecido do hospedeiro, driblando o sistema imunológico e impedindo a fagocitose, além de proteger as células bacterianas da ação de agentes antimicrobianos (Jimenez et al., 2012; Mukherjee et al., 2018; Brindhadevi, 2020).

A Organização Mundial de Saúde (OMS) publicou a primeira lista com os patógenos resistentes a antibióticos que devem ser prioridade para o desenvolvimento de novos antimicrobianos, nessa lista está inserida Pseudomonas aeruginosa (WHO, 2017). Concomitantemente, no Brasil a prevalência de notificações clínicas associadas a pacientes em UTIs adulto $(41 \%)$, neonatal $(23 \%)$ e pediátrica $(28,6 \%)$ com infecções primárias de corrente sanguínea ou com infecções do trato urinário em pacientes adultos $(41,70 \%)$ e pediátricos $(23 \%)$ que tiveram como agente etiológico cepas resistentes de $P$. aeruginosa, estes números representam um problema grave de saúde pública no país (Brasil, 2019). 
Diante da importância clínica de Pseudomonas aeruginosa, o presente artigo teve como objetivo descrever os mecanismos responsáveis pela patogenicidade da espécie bacteriana, com ênfase na formação do biofilme.

\section{Metodologia}

Segundo Pereira e colaboradores (2018), as pesquisas apresentam como principal objetivo, a aquisição e construção de conhecimento. Desse modo, foi realizada uma revisão narrativa sob o ponto de vista teórico.

A pesquisa foi realiza num recorte temporal, entre os anos de 2019 e 2020, mediante revisão de literatura em artigos indexados em bancos de dados eletrônicos, como: Science direct, MEDLINE/PubMed, SciELO (Scientific Electronic Library Online), Nature e LILACS, bem como outras bases de dados não indexadas, como o Google Scholar. Como mecanismos de busca foram usados os operadores booleanos OR e AND em associação dos termos e descritores analisados: "quorum sensing", "Pseudomonas aeruginosa", "biofilm", "virulence factors", "Flagella", "pili", "bacterial adhesion" "polysaccharide" "adhesins" e "biofilm matrix", utilizados na triagem de artigos publicados em inglês entre 2000 e 2020, além de artigos clássicos de grande relevância.

Critérios de inclusão e exclusão foram aplicados para a pesquisa. Quanto aos fatores de inclusão foram selecionados artigos que apresentaram os descritores selecionados, que tivessem relação com o tema abordado, durante o período de interesse estipulado, com abordagem específica sobre o tema estudado e escritos na língua inglesa. Os critérios de exclusão se destinaram a materiais em idiomas diferentes do determinado, fora do recorte temporal e com informações repetidas. Para seleção, os critérios foram aplicados na seguinte ordem: leitura exploratória; leitura seletiva, seleção do material em adequação aos objetivos da pesquisa.

\section{Revisão de Literatura}

\subsection{Pseudomonas aeruginosa}

Pseudomonas aeruginosa é uma espécie bacteriana pertencente à família Pseudomonadaceae classificada com base nas suas características fenotípicas e na homologia do RNAr, se inserido respectivamente, no grupo Florescente e grupo I de RNAr (Palleroni, 2010). É um bacilo Gram-negativo, aeróbio, não formador de esporos que mede 0,5-0,8 $\mu \mathrm{m}$ de largura, 1,53,0 $\mu \mathrm{m}$ de comprimento e apresenta flagelo polar. É uma espécie não fermentadora, com crescimento em temperaturas entre 5 e $42^{\circ} \mathrm{C}$, capaz de oxidar glicose e de metabolizar quaternários de amônio como, acetamida e cetrimida (Palleroni, 2015).

A espécie é produtora de pigmentos hidrossolúveis que lhe conferem colorações peculiares, dentre elas: piocianina (coloração azul) e pioverdina (pigmento verde-amarelado fluorescente), piorrubina (coloração vermelha) e piomelanina (coloração marrom) (MacFaddin, 1985).

\subsection{Quorum sensing}

Durante o processo infeccioso, Pseudomonas aeruginosa libera uma variedade de fatores de virulência, como: elastase, ramnolipídeos, piocianina e protease, estes fatores são responsáveis por sua patogenicidade, uma vez que bloqueiam a resposta imunológica e destroem as células de defesa do hospedeiro (Jimenez et al., 2012).

A liberação desses fatores é mediada por um sistema de comunicação entre as células bacterianas, chamado de Quorum Sensing (QS). Em P. aeruginosa, o QS é composto por três sistemas: las, rhl, e pqs, que regulam a expressão dos genes dos fatores de virulência, e, são controlados por moléculas autoindutoras (Kariminik, Baseri-Salehi \& Kheirkhah, 2017). As moléculas autoindutoras são biossintetizadas nas células bacterianas e liberadas para o meio extracelular. Desta forma, sua 
concentração aumenta conforme a densidade populacional. A bactéria detecta a concentração das moléculas autoindutoras através de um receptor transmembranar que ativa a cascata de estímulos e respostas do QS (Hawver; Jung \& Ng, 2016).

As moléculas autoindutoras, responsáveis pelos sistemas las e rhl, são estruturas de acil-homoserina lactona (AHL) (Figura 1). Quimicamente, apresentam uma porção homosserina lactona ionizada e outra porção de um grupamento acil, que varia entre 4 e 18 carbonos. O radical metílico terminal pode ser substituído por 3-oxo ou 3-hidroxi, com vários graus de saturação. A característica hidrofóbica de AHLs atinge um equilíbrio a partir cadeia lateral hidrofóbica e a porção parcialmente hidrofílica de homosserina lactonizada, que viabiliza a difusão através de membranas celulares e a estabilidade em ambiente aquoso (Churchill \& Chen, 2011).

Figura 1 - Estrutura química das moléculas autoindutoras presentes em Pseudomonas aeruginosa.

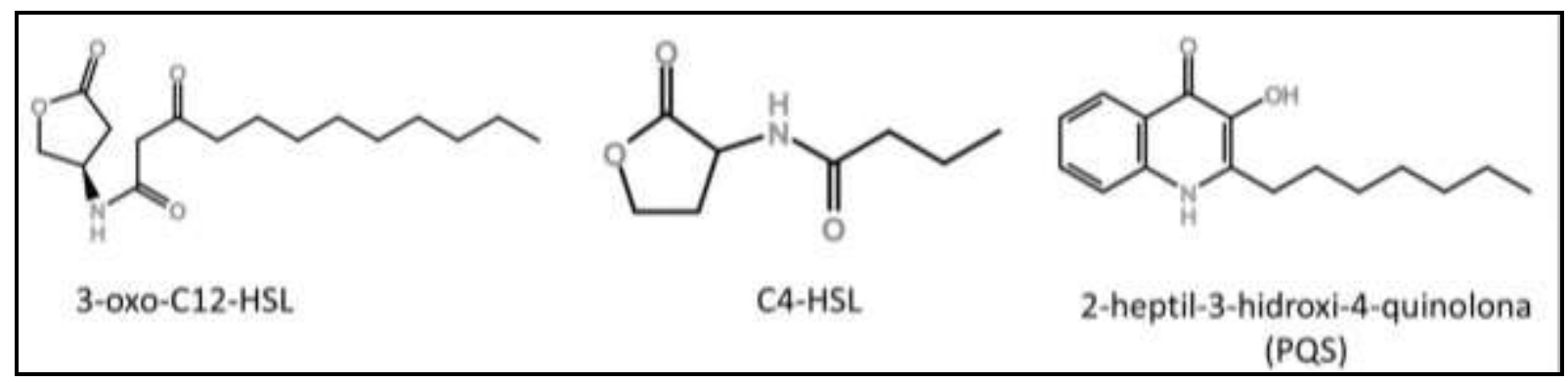

Fonte: Autores (2020)

O sistema las é composto de dois pares de genes LasI e LasR, responsável por produzir e gerar resposta pela molécula indutora N-3-oxo-dodecanoil homoserina lactona (3-oxo-C12-HSL) produzida por LasI sintetase e reconhecida por um regulador transcricional, o LasR. O sistema $r h l$, é controlado a partir da molécula N-butanoil-homoserina lactona (C4-HSL) produzida por RhlI sintetase e detectada pelo regulador transcricional RhlR (Jimenez et al., 2012; Hawver; Jung \& Ng, 2016).

O sistema pqs (Sinal de quinolona de Pseudomonas) funciona a partir de dois autoindutores, a molécula 2-heptil-3hidroxi-4-quinolona (PQS) (Figura 1) e sua precursora, a molécula 2-heptil-4-quinolona (HHQ) (Gallagher et al., 2002). O pqs é ativado quando o fator transcricional PqsR é estimulado pelos autoindutores HHQ ou PQS, amplificando a expressão do opéron pqsABCDE, onde o quinto gene deste operon, $p q s E$, tem como produto a enzima pqsE, uma metalo-hidrolase que estimula a produção de elastase, piocianina e ramnolipídeo (Rampioni et al., 2010; Mukherjee et al., 2018; Soheili et al., 2019).

O sistema $p q s$, pode ser ativado também a partir da interação da molécula 3-oxo-C12-HSL. O sistema pqs é capaz de otimizar a transcrição do gene rhlI, induzindo também a produção de C4-HSL e a expressão do sistema rhl (McKnight; Iglewski \& Pesci, 2000). A expressão de pqsR e pqsABCDE é inibida por C4-HSL. Pode-se dizer que o sistema las é o topo da hierarquia dos sistemas de regulação do quorum sensing, por outro ângulo, o sistema rhl é controlado pelos sistemas las e pqs, porém, parte dos fatores de virulência é ativado por $r h l$. No geral, a união dos sistemas forma uma cascata de ativação que produz reações que serão desencadeadas surgindo um verdadeiro quorum de células (Lee et al., 2013). A Figura 2 traz um breve esquema sobre o processo de funcionamento do quórum sensing de Pseudomonas aeruginosa. 
Figura 2 - Vias de ativação do quorum sensing em Pseudomonas aeruginosa.

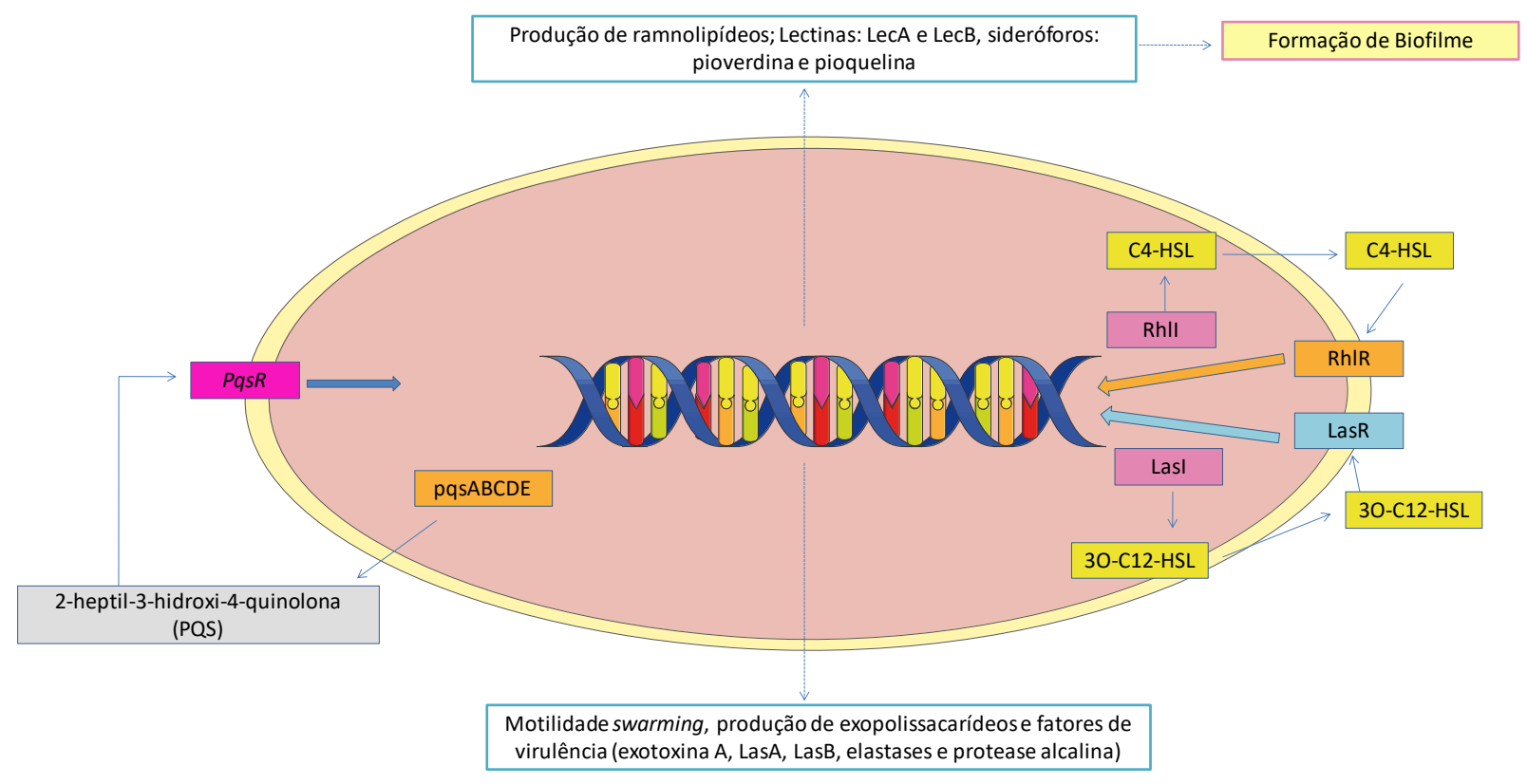

Fonte: Reprodução baseada em Kariminik, Baseri-Salehi \& Kheirkhah (2017)

A produção de fatores de virulência por Pseudomonas aeruginosa durante infecção aguda, ocorre por meio da ativação dos seus genes-alvos a partir dos autoindutores como: A 3-oxo-C12-HSL estimula a biossíntese da exotoxina A, catalase, pilus, formação do biofilme, motilidade por flagelos ou motilidade twitchcing (Kievit et al., 2001); as moléculas C4-HSL e PQS estimulam ramnolipídeos, piocianina, lecitina A e B. Além desses, a PQS estimula também a produção do cianeto de hidrogênio (Jimenez et al., 2012; Nakagami et al., 2015).

\subsection{Biofilme de Pseudomonas aeruginosa}

O biofilme é um fator de virulência importante de Pseudomonas aeruginosa, pois durante a infecção ele protege a população bacteriana contra o ataque das células fagocitárias do hospedeiro e da ação dos antimicrobianos (Taylor; Yeung \& Hancock, 2014; Brindhadevi, 2020), que podem se formar em superfícies bióticas estando relacionadas a infecções locais ou sistêmicas e, superfícies abióticas, como dispositivos médicos (Rybtke et al., 2015).

Estruturalmente, o biofilme consiste em comunidades bacterianas inserida numa matriz exopolissacarídica (EPS) de estrutura tridimensional que fornece à célula bacteriana substrato para seu crescimento e homeostase para sua sobrevivência, protegendo as células das condições ambientais adversas e permitindo a comunicação entre elas através do quorum sensing (QS), que tem papel fundamental na formação do biofilme e tem sido alvo dos pesquisadores na busca por terapias contra infecções de P. aeruginosa (Friedman \& Kolter, 2004; Sharma et al., 2014; Pattnaik et al., 2018).

A formação do biofilme (Figura 3) inicia-se pela adesão reversível das células planctônicas a uma superfície de crescimento (estágio I). Em seguida, as bactérias se ligam de maneira irreversível à superfície, formando micro colônias com a matriz exopolissacarídica (estágio II). O crescimento constante dessas micro colônias resulta em sua expansão e estruturação fenotípica (estágio III). A colonização dos espaços adjacentes, são ocupados por bactérias (estágio IV). Por último, as bactérias que estão no estado séssil se desprendem para colonizar outros locais (estágio V) (Rasamiravaka et al., 2015). 
Figura 3 - Estágios de formação do biofilme.

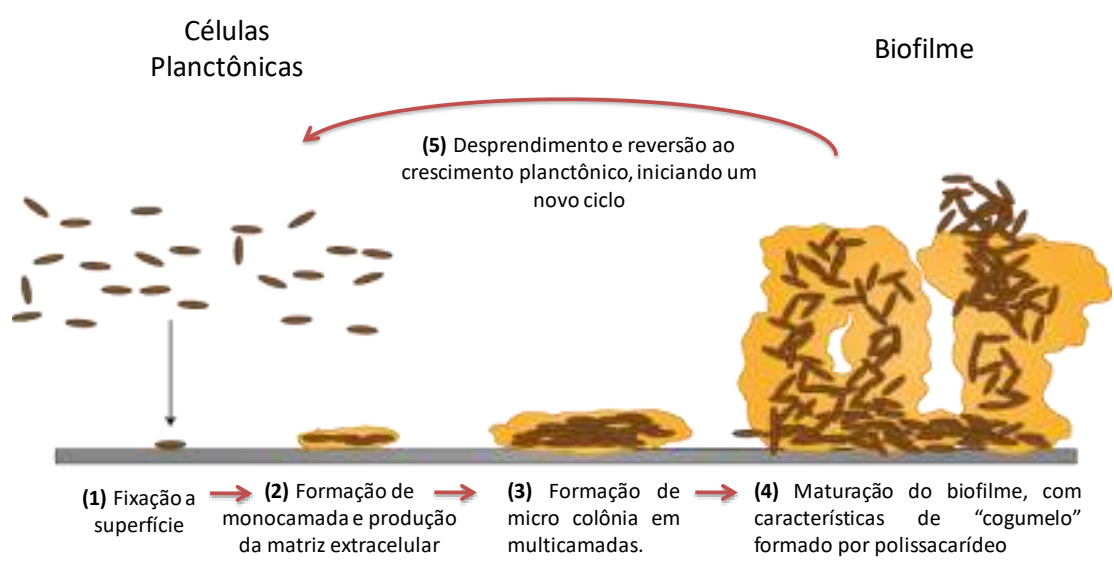

Fonte: Vasudevan, (2014)

A produção da matriz exopolissacarídica (EPS) ocorre na fase em que as células bacterianas apresentam alto grau de agregação. A matriz é composta de polissacarídeos, lipídeos, proteínas, ácidos nucléicos e biossurfactantes, este último auxiliando na aderência das células e na estruturação do biofilme (Flemming \& Wingender, 2010). Os exopolissacarídeos produzidos por Pseudomonas aeruginosa e que estão presentes no biofilme são denominados: Pel, Psl e alginato (Ryder; Byrd \& Wozniak, 2007). Cada um destes apresenta sua função no desenvolvimento do biofilme e na sobrevivência da bactéria. O EPS tem a função de transformar células bacterianas planctônicas em sésseis e auxiliar na aderência das células ao biofilme (Mann \& Wozniak, 2012).

\subsection{Adesinas}

As adesinas provenientes de organelas bacterianas como pili e flagelo são essenciais para auxiliar à formação do biofilme, se ligam as moléculas receptoras glicosiladas no epitélio da célula do hospedeiro e as células bacterianas entre elas. Para se movimentar nas superfícies, Pseudomonas aeruginosa utiliza o seu único flagelo polar e os pili do tipo IV (O’Toole \& Kolter, 1998; Bruzaud et al., 2015).

\subsubsection{Pili}

Pili ou fimbrias são estruturas filamentosas, que se assemelham a pelos localizadas na superfície bacteriana que constituem um importante fator de virulência, com a capacidade de reconhecer as células do tecido do hospedeiro bem como as células do sistema imunológico (Pizarro-Cerdá \& Cossart, 2006).

Em P. aeruginosa estão presentes os pili do tipo IV (PT4) com funções importante para a virulência do patógeno como: aderência a superfícies bióticas e abióticas, formação do biofilme, invasão celular, captação do DNA, motilidade e infecção por bacteriófago (O’Toole \& Kolter, 1998; Bruzaud et al., 2015).

\subsubsection{Flagelo}

Os flagelos apresentam importante papel na virulência das bacterias como quimiotaxia, adesão, colonização e invasão das superfícies bióticas (Ramos; Rumbo \& Sirard, 2004). A motilidade de P. aeruginosa é essencial para formação e maturação do biofilme, os flagelos estão diretamente relacionados com a aderência da célula bacteriana a superfície (O’Toole \& Kolter, 1998) 
Desse modo, o flagelo fixa-se a superfície antes da célula bacteriana através do seu movimento rápido de rotação atuando como uma âncora. A rotação do flagelo continua ativa, se movimentando a partir do ponto que está ancorado. A aderência a superfície é de forma irregular, onde a célula bacteriana começa a se ligar a superfície de modo reversível que evolui para uma ligação irreversível à medida que se liga a maior parte da superfície de contato, expressando alta afinidade a superfícies hidrofóbicas (Bruzaud et al., 2015).

\subsection{Segundo mensageiro di-GMP}

As bactérias utilizam moléculas sinalizadoras para direcionar as condições fisiológicas internas em resposta aos estímulos ambientais controlando a motilidade. O c-di-GMP é uma molécula de sinalização intracelular com a função de controlar a motilidade da bactéria através da ligação com os seus receptores (Wu; Cheng \& Cheng, 2019).

O bis-(3'-5')-ciclico-dimérico-guanosina-monofosfato ou diguanilato cíclico (c-di-GMP) é um segundo mensageiro intracelular que atua na regulação de diversos processos bacterianos. O di-GMP cíclico controla processos celulares nas bactérias, dentre elas, produção de exopolissacarídeos (EPS), fixação e motilidade (D’Argenio \& Miller, 2004).

As vias de sinalização dependentes de c-di-GMP (ou di-GMP cíclico) administram a interação das bactérias com as superfícies bióticas e abióticas. Do ponto de vista sensorial, bacteriano, quando as concentrações de c-di-GMP estão baixas significa que as células estão se movendo pelo efeito do flagelo e do pili retrátil. Quando em concentrações crescentes promovem a expressão da matriz adesiva, comportamento multicelular e formação de biofilme (Jenal \& Malone, 2006; Römling; Galperin \& Gomelsky, 2013).

\subsection{Matriz de biofilme}

\subsubsection{Expolissacarídeos}

Os exopolissacarídeos representam um importante componente da matriz do biofilme. Em Pseudomonas aeruginosa os polissacarídeos extracelulares relacionados ao biofilme são três, alginato, pel e psl (Franklin et al., 2011).

\subsubsection{Alginato}

Quimicamente, o alginato é um polímero acetilado, de alto peso molecular composto de monômeros combinados de ácido L-gulorônico e D-manurônico unidos por ligação glicosídica entre os carbonos 1 e 4 (Evans \& Linker, 1973), esta ligação confere rigidez a estrutura. A função desta molécula vai além da estabilidade estrutural que ela oferece ao biofilme (Franklin et al., 2011).

P. aeruginosa quebra o polímero em oligossacarídeos curtos, a partir da ação da alginato liase $(\operatorname{alg} L)$, que reduz capacidade de ancorar as células, ocasionando a separação das células bacterianas, e consequente dispersão do microorganismo para colonizarem outros locais (Skariyachan et al., 2018).

O alginato é detectado em maior concentração em cepas mucoides, e apresenta resistência fagocitose e despolimerização por radicais livres, produzidos por macrófagos e neutrófilos do hospedeiro (Simpson; Smith \& Dean, 1993; Ryder; Byrd \& Wozniak, 2007). A superprodução de alginato é considerada uma forma de proteção das células aos estresses ambientais ou químicos (Tan et al., 2018).

\subsubsection{Psl}

Quimicamente, $p s l$ é composto por pentassacarídeos com repeticções dinstintas dos açucares d-manose, d-glicose e 1ramnose. Um pool de nucleotídeos de açucares precursores, GDP-d-manose, UDP-d-glicose e d-TDP-I-ramnose, estão 
comprometidos com a geração de $p s l$ e com a sua adesão superficial. O exopolissacarídeo é encontrado em duas formas: associados a células bacterianas, nesse caso é caracterizado por ter um alto peso molecular, e em sobrenadante de cultura livre de células, quando essas moléculas apresentam baixo peso molecular (Byrd et al., 2009; Mann \& Wozniak, 2012).

O psl é importante para adesão inicial das células sésseis em uma superfície biótica ou abiótica (Byrd et al., 2009), por se distribuir de forma helicoidal ao redor da superfície da célula, mantém a organização do biofilme. Quando ligado as células tem a capacidade de conectá-las, e envolvê-las dentro de uma matriz. Na estrutura tridimensional, do biofilme, o psl é observado na periferia da micro colônia. Após o amadurecimento, uma cavidade no centro inferior da micro colônia é formada, por morte e lise bacteriana, para que ocorra a degradação do $p s l$ e destruição da matriz, objetivando o desprendimento das células bacterianas para colonização de outros locais (Skariyachan et al., 2018).

\subsubsection{Pel}

O pel é um exopolissacarídeo catiônico, com estrutura química ainda não foi elucidada totalmente, no entanto, acredita-se ser um polissacarídeo de glicose (Friedman \& Kolter, 2004; Colvin et al., 2011). As cepas de Pseudomonas aeruginosa não-mucoides, utilizam o $\mathrm{Pel}$ e o $\mathrm{Psl}$ como complexos estruturais primários, uma vez que elas não produzem quantidades suficientes de alginato. Do ponto de vista funcional, o Pel exerce o papel de proteger o biofilme em P. aeruginosa e aumenta a resistência contra antimicrobianos (Colvin et al., 2012).

\subsubsection{DNA extracelular (eDNA)}

Em Pseudomonas aeruginosa o eDNA é um dos principais componentes do biofilme, funciona como conector intercelular e estabilizador da matriz (Gloag et al., 2013). O eDNA atua mutuamente com o $P s l$ para formar uma rede a partir de eDNA-Psl sendo a estrutura inicial do biofilme. O eDNA funciona fortalecendo o biofilme, como fonte de nutrientes em períodos de carência nutricional, fornece resistência aos antimicrobianos e ajuda na expansão do biofilme (Wang et al., 2015).

Em $P$. aeruginosa o eDNA é produzido pela lise de uma subpopulação bacteriana, se encontra localizado em estruturas multicelulares do biofilme, e sua liberação das células ocorre por autólise (Montanaro et al., 2011). O eDNA garante alinhamento do arranjo celular dentro do biofilme, promovendo o desenvolvimento eficiente de células bacterianas para a periferia das micro colônias e permitindo a extensão do biofilme (Gloag et al., 2013).

\section{Conclusão}

O biofilme formado por $P$. aeruginosa é um problema de saúde pública devido ao aumento da resistência a antimicrobiana associada a esta estrutura bacteriana. A formação da matriz é regulada pelo Quorum sensing, o que dificulta a compreensão dos mecanismos de virulência expressos por $P$. aeruginosa e o desenvolvimento de métodos eficazes para destruir o biofilme.

Portanto, a elucidação da interação entre o QS, a formação do biofilme bem como a produção dos fatores de virulência contribui significativamente para o desenvolvimento de novas alternativas terapêuticas que possam erradicar os mecanismos que causam infecções resistentes por $P$. aeruginosa. Dessa forma, sugere-se o aprofundamento do estudo molecular da formação do biofilme de $P$. aeruginosa e a busca concomitante por alternativas terapêuticas para interromper o mecanismo do seu Quorum sensing.

\section{Referências}

Brasil (2019). Agência Nacional de Vigilância Sanitária. Boletim Segurança do Paciente e Qualidade em Serviços de Saúde $n^{\circ} 20:$ Avaliação dos indicadores nacionais das IRAS e RM 2018. Brasília: ANVISA. https://bit.ly/2MRfYvE 
Brindhadevi, K., LewisOscar, F., Mylonakis, E., Shanmugam, S., Verma, T. N., \& Pugazhendhi, A. (2020). Biofilm and Quorum sensing mediated pathogenicity in Pseudomonas aeruginosa. Process Biochemistry. https://doi.org/10.1016/j.procbio.2020.06.001

Bruzaud, J., Tarrade, J., Coudreuse, A., Canette, A., Herry, J. M., de Givenchy, E. T., Darmaninc, T., Guittardc, F., Guilbau da, M., \& Bellon-Fontaine, M. N. (2015). Flagella but not type IV pili are involved in the initial adhesion of Pseudomonas aeruginosa PAO1 to hydrophobic or superhydrophobic surfaces. Colloids and Surfaces B: Biointerfaces, 131, 59-66. https://doi.org/10.1016/j.colsurfb.2015.04.036

Byrd, M. S., Sadovskaya, I., Vinogradov, E., Lu, H., Sprinkle, A. B., Richardson, S. H., Ma, L., Ralston, B., Parsek, M. R., Anderson, E. M., Lam, J. S., \& Daniel J. Wozniak (2009). Genetic and biochemical analyses of the Pseudomonas aeruginosa Psl exopolysaccharide reveal overlapping roles for polysaccharide synthesis enzymes in Psl and LPS production. Molecular microbiology, 73(4), 622-638. https://doi.org/10.1111/j.1365-2958.2009.06795.x

Churchill, M. E., \& Chen, L. (2011). Structural basis of acyl-homoserine lactone-dependent signaling. Chemical reviews, 111(1), 68-85. https://doi.org/10.1021/cr1000817

Colvin, K. M., Gordon, V. D., Murakami, K., Borlee, B. R., Wozniak, D. J., Wong, G. C., \& Parsek, M. R. (2011). The pel polysaccharide can serve a structural and protective role in the biofilm matrix of Pseudomonas aeruginosa. PLoS Pathog, 7(1), e1001264. https://doi.org/10.1371/journal.ppat.1001264

Colvin, K. M., Irie, Y., Tart, C. S., Urbano, R., Whitney, J. C., Ryder, C., Howell, P. L., Wozniak, D. J., \& Parsek, M. R. (2012). The Pel and Psl polysaccharides provide Pseudomonas aeruginosa structural redundancy within the biofilm matrix. Environmental microbiology, 14(8), 1913-1928. https://doi.org/10.1111/j.1462-2920.2011.02657.x

D'Argenio, D. A., \& Miller, S. I. (2004). Cyclic di-GMP as a bacterial second messenger. Microbiology, 150(8), 2497-2502. https://doi.org/10.1099/mic.0.27099-0

Davies, J. C. (2002). Pseudomonas aeruginosa in cystic fibrosis: pathogenesis and persistence. Paediatric respiratory reviews, 3(2), 128-134. https://doi.org/10.1016/S1526-0550(02)00003-3

Evans, L. R., \& Linker, A. (1973). Production and characterization of the slime polysaccharide of Pseudomonas aeruginosa. Journal of bacteriology, 116(2), 915-924. https://doi.org/10.1128/JB.116.2.915-924.1973

Flemming, H. C., \& Wingender, J. (2010). The biofilm matrix. Nature reviews microbiology, 8(9), 623-633. https://doi.org/10.1038/nrmicro2415

Franklin, M. J., Nivens, D. E., Weadge, J. T., \& Howell, P. L. (2011). Biosynthesis of the Pseudomonas aeruginosa extracellular polysaccharides, alginate, Pel, and Psl. Frontiers in microbiology, 2, 167. https://doi.org/10.3389/fmicb.2011.00167

Friedman, L., \& Kolter, R. (2004). Two genetic loci produce distinct carbohydrate-rich structural components of the Pseudomonas aeruginosa biofilm matrix. Journal of bacteriology, 186(14), 4457-4465. https://doi.org/10.1128/JB.186.14.4457-4465.2004

Gallagher, L. A., McKnight, S. L., Kuznetsova, M. S., Pesci, E. C., \& Manoil, C. (2002). Functions required for extracellular quinolone signaling by Pseudomonas aeruginosa. Journal of bacteriology, 184(23), 6472-6480. https://doi.org/10.1128/JB.184.23.6472-6480.2002

Gloag, E. S., Turnbull, L., Huang, A., Vallotton, P., Wang, H., Nolan, L. M., Mililli, L., Hunt, C., Lu, J., Osvath, S. R., Monahan, L. G., Cavaliere, R., Charles, I. G., Wand, M. P., Gee, M. L., Prabhakar, R., \& Whitchurch, C. B. (2013). Self-organization of bacterial biofilms is facilitated by extracellular DNA. Proceedings of the National Academy of Sciences, 110(28), 11541-11546. https://doi.org/10.1073/pnas.1218898110

Hawver, L. A., Jung, S. A., \& Ng, W. L. (2016). Specificity and complexity in bacterial quorum-sensing systems. FEMS microbiology reviews, 40(5), 738752. https://doi.org/10.1093/femsre/fuw014

Jenal, U., \& Malone, J. (2006). Mechanisms of cyclic-di-GMP signaling in bacteria. Annu. Rev. Genet., 40, 385-407. https://doi.org/10.1146/annurev.genet.40.110405.090423

Jimenez, P. N., Koch, G., Thompson, J. A., Xavier, K. B., Cool, R. H., \& Quax, W. J. (2012). The multiple signaling systems regulating virulence in Pseudomonas aeruginosa. Microbiology and Molecular Biology Reviews, 76(1), 46-65. https://doi.org/10.1128/MMBR.05007-11

Johansen, H. K., Kovesi, T. A., Koch, C., Corey, M., Høiby, N., \& Levison, H. (1998). Pseudomonas aeruginosa and Burkholderia cepacia infection in cystic fibrosis patients treated in Toronto and Copenhagen. Pediatric pulmonology, 26(2), 89-96. https://doi.org/10.1002/(SICI)1099-0496(199808)26:2<89::AIDPPUL3>3.0.CO;2-C

Kariminik, A., Baseri-Salehi, M., \& Kheirkhah, B. (2017). Pseudomonas aeruginosa quorum sensing modulates immune responses: an updated review article. Immunology letters, 190, 1-6. https://doi.org/10.1016/j.imlet.2017.07.002

Kievit, T. R., Gillis, R., Marx, S., Brown, C., \& Iglewski, B. H. (2001). Quorum-sensing genes in Pseudomonas aeruginosa biofilms: their role and expression patterns. Applied and environmental microbiology, 67(4), 1865-1873. https://doi.org/10.1128/AEM.67.4.1865-1873.2001

Lee, J., Wu, J., Deng, Y., Wang, J., Wang, C., Wang, J., Chang, C., Dong, Y., Williams, P., \& Zhang, L. H. (2013). A cell-cell communication signal integrates quorum sensing and stress response. Nature chemical biology, 9(5), 339. https://doi.org/10.1038/nchembio.1225

MacFaddin, J. F. (1985). Media for the isolation-cultivation-identification-maintenance of medical bacteria, vol. 1 Williams \& Wilkins. Baltimore, MD.

Mann, E. E., \& Wozniak, D. J. (2012). Pseudomonas biofilm matrix composition and niche biology. FEMS microbiology reviews, 36(4), 893-916. https://doi.org/10.1111/j.1574-6976.2011.00322.x

McKnight, S. L., Iglewski, B. H., \& Pesci, E. C. (2000). The Pseudomonas quinolone signal regulates rhl quorum sensing in Pseudomonas aeruginosa. Journal of bacteriology, 182(10), 2702-2708. https://doi.org/10.1128/JB.182.10.2702-2708.2000

Montanaro, L., Poggi, A., Visai, L., Ravaioli, S., Campoccia, D., Speziale, P., \& Arciola, C. R. (2011). Extracellular DNA in biofilms. The International journal of artificial organs, 34(9), 824-831. https://doi.org/10.5301/ijao.5000051 
Mukherjee, S., Moustafa, D. A., Stergioula, V., Smith, C. D., Goldberg, J. B., \& Bassler, B. L. (2018). The PqsE and RhlR proteins are an autoinducer synthase-receptor pair that control virulence and biofilm development in Pseudomonas aeruginosa. Proceedings of the National Academy of Sciences, 115(40), E9411-E9418. https://doi.org/10.1073/pnas.1814023115

Nakagami, G., Minematsu, T., Morohoshi, T., Yamane, T., Kanazawa, T., Huang, L., Asada, M., Nagase, T., Ikeda, S., Ikeda, T., \& Sanada, H. (2015). Pseudomonas aeruginosa quorum-sensing signaling molecule N-3-oxododecanoyl homoserine lactone induces matrix metalloproteinase 9 expression via the AP1 pathway in rat fibroblasts. Bioscience, Biotechnology, and Biochemistry, 79(10), 1719-1724. https://doi.org/10.1080/09168451.2015.1056509

O'Toole, G. A., \& Kolter, R. (1998). Flagellar and twitching motility are necessary for Pseudomonas aeruginosa biofilm development. Molecular microbiology, 30(2), 295-304. https://doi.org/10.1046/j.1365-2958.1998.01062.x

Palleroni, N. J. (2010). The Pseudomonas story. Environmental microbiology, 12(6), 1377-1383. https://doi.org/10.1111/j.1462-2920.2009.02041.x

Palleroni, N. J. (2015). Pseudomonas. Bergey's manual of systematics of archaea and bacteria. https://books.google.com.br/

Pattnaik, S. S., Ranganathan, S., Ampasala, D. R., Syed, A., Ameen, F., \& Busi, S. (2018). Attenuation of quorum sensing regu lated virulence and biofilm development in Pseudomonas aeruginosa PAO1 by Diaporthe phaseolorum SSP12. Microbial pathogenesis, 118, 177-189. https://doi.org/10.1016/j.micpath.2018.03.031

Pereira, A. S., Shitsuka, D. M., Parreira, F. J., \& Shitsuka, R. (2018). Metodologia da pesquisa científica. [e-book]. Santa Maria. Ed. UAB/NTE/UFSM. Retrieved from: https://repositorio.ufsm.br/bitstream/handle/1/15824/Lic_Computacao_Metodologia-Pesquisa-Cientifica.pdf?sequence=1.

Pizarro-Cerdá, J., \& Cossart, P. (2006). Bacterial adhesion and entry into host cells. Cell, 124(4), 715-727. https://doi.org/10.1016/j.cell.2006.02.012

Ramos, H. C., Rumbo, M., \& Sirard, J. C. (2004). Bacterial flagellins: mediators of pathogenicity and host immune responses in mucosa. Trends in microbiology, 12(11), 509-517. https://doi.org/10.1016/j.tim.2004.09.002

Rampioni, G., Pustelny, C., Fletcher, M. P., Wright, V. J., Bruce, M., Rumbaugh, K. P., Heeb, S., Cámara, M., \& Williams, P. (2010). Transcriptomic analysis reveals a global alkyl-quinolone-independent regulatory role for PqsE in facilitating the environmental adaptation of Pseudomonas aeruginosa to plant and animal hosts. Environmental microbiology, 12(6), 1659-1673. https://doi.org/10.1111/j.1462-2920.2010.02214.x

Rasamiravaka, T., Labtani, Q., Duez, P., \& El Jaziri, M. (2015). The formation of biofilms by Pseudomonas aeruginosa: a review of the natural and synthetic compounds interfering with control mechanisms. BioMed research international, 2015. https://doi.org/10.1155/2015/759348

Römling, U., Galperin, M. Y., \& Gomelsky, M. (2013). Cyclic di-GMP: the first 25 years of a universal bacterial second messenger. Microbiology and Molecular Biology Reviews, 77(1), 1-52. https://doi.org/10.1128/MMBR.00043-12

Rybtke, M., Hultqvist, L. D., Givskov, M., \& Tolker-Nielsen, T. (2015). Pseudomonas aeruginosa biofilm infections: community structure, antimicrobial tolerance and immune response. Journal of molecular biology, 427(23), 3628-3645. https://doi.org/10.1016/j.jmb.2015.08.016

Ryder, C., Byrd, M., \& Wozniak, D. J. (2007). Role of polysaccharides in Pseudomonas aeruginosa biofilm development. Current opinion in microbiology, 10(6), 644-648. https://doi.org/10.1016/j.mib.2007.09.010

Sharma, G., Rao, S., Bansal, A., Dang, S., Gupta, S., \& Gabrani, R. (2014). Pseudomonas aeruginosa biofilm: potential therapeutic targets. Biologicals, 42(1), 1-7. https://doi.org/10.1016/j.biologicals.2013.11.001

Simpson, J. A., Smith, S. E., \& Dean, R. T. (1993). Alginate may accumulate in cystic fibrosis lung because the enzymatic and free radical capacities of phagocytic cells are inadequate for its degradation. Biochemistry and molecular biology international,30(6), 1021-1034. Retrived from: https://europepmc.org/article/med/8220249

Skariyachan, S., Sridhar, V. S., Packirisamy, S., Kumargowda, S. T., \& Challapilli, S. B. (2018). Recent perspectives on the molecular basis of biofilm formation by Pseudomonas aeruginosa and approaches for treatment and biofilm dispersal. Folia microbiologica, 63(4), 413-432. https://doi.org/10.1007/s12223-018-0585-4

Soheili, V., Tajani, A. S., Ghodsi, R., \& Bazzaz, B. S. F. (2019). Anti-PqsR compounds as next-generation antibacterial agents against Pseudomonas aeruginosa: A review. European journal of medicinal chemistry, 172, 26-35. https://doi.org/10.1016/j.ejmech.2019.03.049

Tan, Q., Ai, Q., Xu, Q., Li, F., \& Yu, J. (2018). Polymorphonuclear leukocytes or hydrogen peroxide enhance biofilm development of mucoid Pseudomonas aeruginosa. Mediators of inflammation, 2018. https://doi.org/10.1155/2018/8151362

Taylor, P. K., Yeung, A. T., \& Hancock, R. E. (2014). Antibiotic resistance in Pseudomonas aeruginosa biofilms: towards the development of novel antibiofilm therapies. Journal of Biotechnology, 191, 121-130. https://doi.org/10.1016/j.jbiotec.2014.09.003

Vasudevan, R. (2014). Biofilms: microbial cities of scientific significance. J Microbiol Exp, 1(3), 84-97. 10.15406/jmen.2014.01.00014

Wang, S., Liu, X., Liu, H., Zhang, L., Guo, Y., Yu, S., Wozniak, D. J., \& Ma, L. Z. (2015). The exopolysaccharide Psl-eDNA interaction enables the formation of a biofilm skeleton in Pseudomonas aeruginosa. Environmental microbiology reports, 7(2), 330-340. https://doi.org/10.1111/1758-2229.12252

World Health Organization (2017) Global priority list of antibiotic-resistant bacteria to guide research, discovery, and development of new antibiotics, https://www.who.int/medicines/ publications/global-priority-list-antibiotic-resistant-bacteria/en/.

Wu, Y. K., Cheng, N. C., \& Cheng, C. M. (2019). Biofilms in chronic wounds: pathogenesis and diagnosis. Trends in biotechnology, 37(5), 505-517. https://doi.org/10.1016/j.tibtech.2018.10.011 